\title{
Spatial Identification of Potential Dump Disposal Sites for Effective Waste Management in the Sunyani Municipality, Ghana
}

\author{
Swidbert Höflinger ${ }^{1}$, Mary Antwi ${ }^{2}$, Ampah Amproche Amprofi ${ }^{2}$, Amos Tiereyangn Kabo-Bah ${ }^{1}$ \\ ${ }^{1}$ Department of Civil and Environmental Engineering, University of Energy and Natural Resources, Sunyani, Ghana \\ ${ }^{2}$ Department of Environmental Management, University of Energy and Natural Resources, Sunyani, Ghana \\ Email: swidbert.hoeflinger@student-hfr.de,mary.antwi@uenr.edu.gh,ampahamprofi@gmail.com,amos.kabobah@uenr.edu.gh
}

How to cite this paper: Höflinger, S., Antwi, M., Amprofi, A. A., \& Kabo-Bah, A. T. (2020). Spatial Identification of Potential Dump Disposal Sites for Effective Waste Management in the Sunyani Municipality, Ghana. Journal of Geoscience and Environment Protection, 8, 93-111. https://doi.org/10.4236/gep.2020.811005

Received: August 2, 2020

Accepted: November 10, 2020

Published: November 13, 2020

Copyright $\odot 2020$ by author(s) and Scientific Research Publishing Inc. This work is licensed under the Creative Commons Attribution International License (CC BY 4.0).

http://creativecommons.org/licenses/by/4.0/

\begin{abstract}
One daunting task faced by waste managers is to appropriately identify safe sites for waste disposal and this study combined expert knowledge, field observations and GIS-based modelbuilder to model and identify suitable dumpsites. Overview of the study area confirmed the random siting of dumpsites that poses threat to environmental safety. Land use and land cover classification produced an overall accuracy of $81.97 \%$ with kappa coefficient $=0.78$, which was employed in the suitability search criteria. Other key derived parameters vital for safe dumpsite locations were distances to catchment $>100$ $\mathrm{m}$, distances to water bodies $>100 \mathrm{~m}$, soil characteristics-clayey, topology (slope of 2 and 4) and geology-Granitoids. The weightings (\%) obtained for the key parameters were: water $=32$, connection to catchment area $=28$, topology $=23$, soil $=10$ and geology $=7$. The exclusion criteria and suitability analysis, based on assigned suitable values from the key weighted parameters in the modelbuilder, produced a map of potential waste disposal sites rating them as most suitable, suitable and less suitable for the Sunyani Municipality. The model for the site identification could be used as a guideline to provide first and quick impression on potential waste disposal sites for stakeholders in waste management. The suitable sites give an indicator for sites with the least possible environmental impact. The study however recommends that for specific locations, further in-depth research be done to suit site-specific conditions in order to improve accuracy.
\end{abstract}

\section{Keywords}

Waste Disposal, Modelbuilder, Suitability Analysis, Site Identification, Environmental Safety, Pollution 


\section{Introduction}

Ghana has witnessed a constant growth in urbanisation since 1960 with a 23.1 percent of the population living in urban areas to 50.9 percent in 2010 (GSS, 2012). This growth is associated with problems of proper waste management and disposal among the populace that have to be provided with waste management services. A UN-Habitat report indicated that 9 out of 10 cities are faced with serious waste management problems in Africa (UNHSP, 2003). According to the report, the issue is correlated and enhanced by the growing wealth in the country; thus, growing wealth increases the consumption of local population thereby increasing the total amount of generated waste by the populace. This effect is visible to a greater extent in urban rather than rural areas, as people use more packaged goods in the cities (Bhada-Tata \& Hoornweg, 2012).

In Ghana, an average amount of waste generated in an urban area is about $0.72 \mathrm{~kg} /$ day $/$ capita whereas the rural areas generate an average of $0.28 \mathrm{~kg} /$ day/capita (Miezah et al., 2015). The difference of $0.44 \mathrm{~kg} /$ day/capita shows that the amount being generated is doubled in urbanized regions which leads to the conclusion that focus on issues of waste in the cities should be a major priority in order to gain knowledge and experience in their management. The direct impacts of an improved waste management situation are easier to measure and to observe in a more densely populated area, as the samples taken from such areas cover smaller spaces with a higher impact and therefore have an increased accuracy (UNEP, 2005).

The impacts of waste management can be classified under different topics, for example, the environment or human health related issues (Ferronato \& Torretta, 2019). The environmental aspect of waste management and disposal needs consideration in the process of targeting the waste management system as academic research by providing more and accurate information. Several articles have been written on this topic focusing on different aspects, e.g. the outcomes of released plastics into the environment in the context of the chemical side-effect on wildlife and the human species (Talsness et al., 2009) or the impacts of disposal sites on surface water (Miwornunyuie et al., 2016). A baseline can therefore be drawn that exposure to waste and debris has a concerning effect on the environment and human health therefore, proper management and choice of disposal sites must be established by responsible authorities for which this study proposes an intervention.

A challenge in waste management practices noticed in Ghana is littering alongside roads, in gutters, in burning trash piles or on illegal dumps (Badoe, 2015). This originates failures and insufficiencies along the whole process of waste management. Waste management as a system consists of the following steps: collection, transfer, preparation, separation, recycling, disposal and treatment of the disposal site (Adu-Boahen et al., 2014). Each of these processes needs examination in order to advance and improve the system, which has been proven to be successful. The examination of household waste in Ghana, for example, showed that the highest share in its composition is organic matter con- 
sisting over 50 percent of the total waste followed by plastics and paper both making around 10 percent of the generated waste (Miezah et al., 2015). This situation highlights the key elements in waste management which are the varying disposal methods of these resources (Singh et al., 2014). In Ghana however, the approach of disposal used in the public waste management systems and in the private sector threatens environmental health since majority of these dump sites do not meet standards and are illegally sited (Adu-Boahen et al., 2014).

The waste management hierarchy indicates different options to reduce and manage waste starting from the top with the most favoured options; prevention, reduction, recycling, recovery and disposal as least favoured (Rodic-Wiersma, 2013). However, it could be stated that in order to decrease the impact of the waste in a short term, establishing proper disposal sites could help and initiate a transition to more technological solutions when the basic needs are met (Nnorom \& Osibanjo, 2008). Several studies (Henry et al., 2006; Jerie \& Zulu, 2017; Idowu et al., 2019) have been done in developing countries on how to construct simple solutions, but appropriate promotion is lacking. These studies also emphasize on preparation and management of disposal sites which is a key issue at the moment. But it must be noted that with a well-prepared site the impacts of a disposal site on the environment and the human health can be reduced so that the management of the waste continues from there. For example, with a working leachate treatment of the drained water from waste disposal sites, concentrations of pollutants entering water bodies can be minimized. And this can be accomplished when the siting of a dump considers factors such as the drainage capacities of soils at the site because aftercare is expensive and reconstructions take up more time. A model, like the model builder used in this study, combines key factors such ability of the chosen site to serve as buffer zones, proximity to roads, settlements, protected areas, waterbodies, etc to generate maps that help in decision making in the choice of suitable areas for dumpsites in order to lessen negative environmental impacts.

In addition, the flexibility in the model adjustment provides waste managers the opportunity to integrate their own approach to the identification process and apply it to specific site conditions. Since the model runs on open data, derived results could also be adjusted by waste management operators in any location in Ghana and Western Africa to suit their parameter preferences. The aims of this study therefore were to 1) analyse the current waste disposal practices and 2) create a model that will identify the most suitable site for waste disposal based on weighted parameters within the Sunyani Municipality of Ghana. The objectives are aimed at addressing the usual means of sitting dumpsites by performing basically proximity analysis without considerations to suitability of geological and soil properties of the identified site. This study employs geo-technical means whereby land use/cover assessment has been combined with relevant environmental parameters in identifying dumpsites in the Municipality that contribute to curbing waste pollution. This study will provide an enhanced method for site identification for waste disposal in Ghana. 


\section{Materials and Methods}

\subsection{Study Area}

The research was carried out in the newly created Bono region in the western part of Ghana, precisely within the Sunyani Municipality and the Sunyani West district. The study area is $1565.55 \mathrm{~km}^{2}$ and geographically lies between latitude $7^{\circ} 19^{\prime} \mathrm{N}$ and $7^{\circ} 35^{\prime} \mathrm{N}$ and longitudes $2^{\circ} 08^{\prime} \mathrm{W}$ and $2^{\circ} 31^{\prime} \mathrm{W}$. The city of Sunyani is located in a light forested area with a considerable amount of vegetation growing within the city borders except the centre of the town. Surrounding the city of Sunyani within the study area are 42 small towns and villages. The area lies between gentle sloped hills and the closest and biggest river with the catchment is the Tano River, located southeast of the Sunyani city centre. The area is also characterised by temporary streams due to seasonal divided distribution of the rain. The smaller streams with small-scale water catchment areas dry out in the dry season but are used as flood discharge ways in the rainy season. With temporary surface runoff these streams feed the surrounding vegetation and can evolve into minor wetlands, which are used by the local population for biomass production, irrigation, washing and bathing. Recent research carried out in the study area on water quality assessment in correlation with a waste disposal site in Sunyani by (Miwornunyuie et al., 2016) indicated that a tributary of the Tano River in close proximity to a disposal site had significantly higher concentrations of pollutants than allowed when compared to the Environmental Protection Agency standards at the measuring points, mid and downstream area. The location of the study area has been depicted in Figure 1.

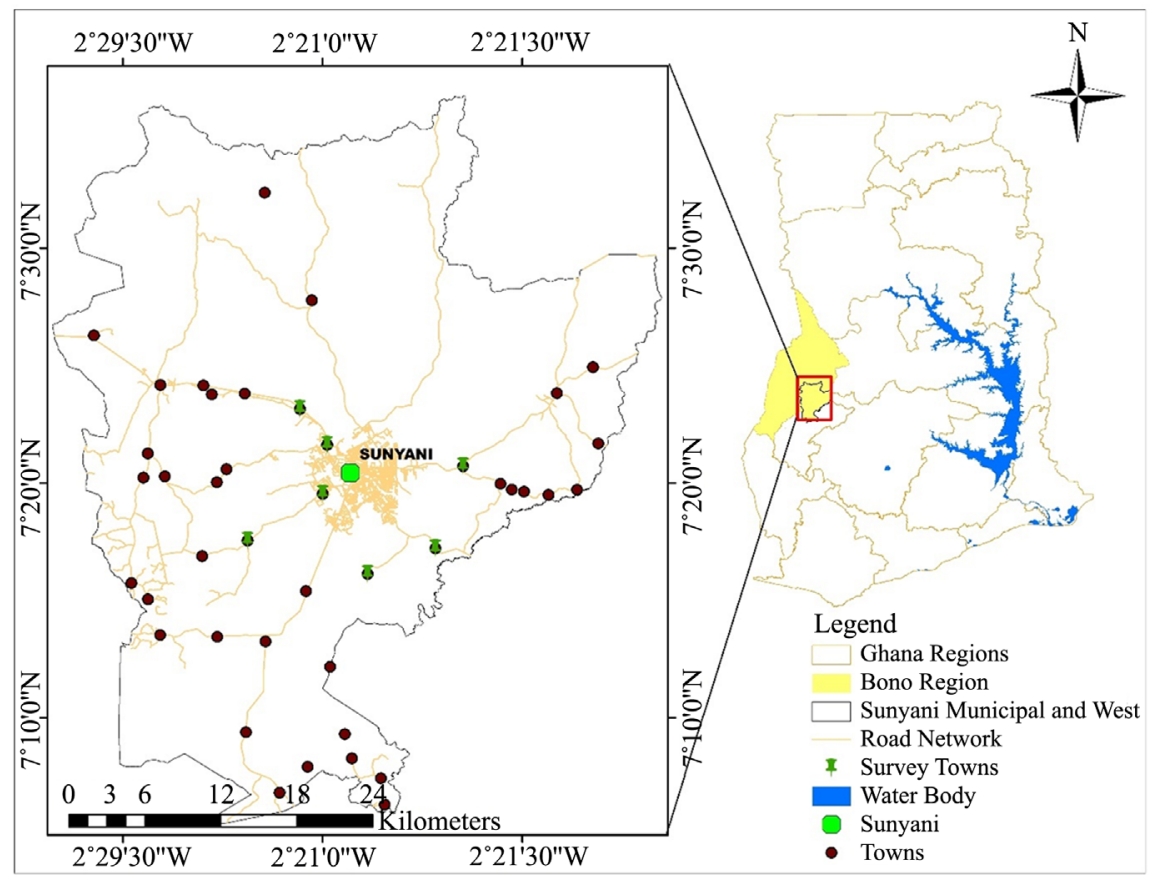

Figure 1. Study area map of Sunyani Municipality and the Sunyani west district (Author's own construct, 2019). 


\subsection{Methodology}

\subsubsection{GIS and Remote Sensing Data Collection}

The geographic data used for the research were obtained from the database portals of open sources for non-commercial uses. The soil data, raster and shapefiles and their sources are listed in Table 1.

The ALOS-2 DEM was chosen for this work based on the outcome of a research that compared Advanced Spaceborne Thermal Emission and Reflection Radiometer (ASTER), Shuttle Radar Topographic Mission (SRTM) and ALOSs DEMs in terms of accuracy with the outcome of ALOS-2 DEM being the most accurate (Alganci et al., 2018), and more so very current DEM was readily available for download. The DEM dataset obtained was updated in March 2019 prior to the usage in the model.

The Landsat 8 scenes for the study area were acquired from the USGS. The imagery was chosen based on the fact that it contained the least cloud cover for the study area with a factor of 1.39 . The date the scenes were photographed was the $31 / 03 / 2019$, with a resolution of 30 by 30 meters, apart from the panchromatic band which has a resolution of 15 by 15 meters.

The OSM shapefiles are open data provided by different hosts. For this thesis, the host "Geofabrik Karlsruhe" was chosen based on the availability of data in the research area and its accuracy especially for smaller roads. The soil datasets were also obtained from the ISRIC and AfSIS websites (ISRIC, 2017). The data were modified for this study with the ISRIC and AfSIS soil data "AfSoilGrids 250 $m$ maps" due to the extent and the quantity of data. The resolution provided was 250 by 250 meters in a dataset for the whole Africa. The soil data were obtained for the following depths, $0-5 \mathrm{~cm}, 5-15 \mathrm{~cm}, 15-30 \mathrm{~cm}, 30-60 \mathrm{~cm}, 60-100 \mathrm{~cm}$, $100-200 \mathrm{~cm}$ as single layers.

The shapefiles for the jurisdictions and towns of the study area were provided by the Earth Observation Research and Innovation Centre (EORIC) at UENR, Sunyani, Ghana.

Table 1. Obtained open database and their sources used for the analysis of waste disposal sites in Sunyani, Ghana.

\begin{tabular}{ccc}
\hline Feature & Source & Country \\
\hline $\begin{array}{c}\text { Digital Elevation Model (DEM) } \\
\text { of Ghana }\end{array}$ & Advanced Land Observing & Japan Aerospace \\
Landsat 8 scene & Satellite 2 (ALOS-2) & Exploration Agency \\
OpenStreetMap (OSM) Shapefiles & US Geological Survey (USGS) & United States \\
& Geofabrik Karlsruhe & Germany \\
Soil data & International Soil Reference and & Netherlands \\
& Information Centre (ISRIC) & \\
Borders and Towns of Sunyani & Africa Soil Information & Netherlands \\
Municipality and Sunyani West district & Satural Resources (UENR) & Ghana \\
\hline
\end{tabular}




\subsubsection{Data Coordinate System Representation}

The coordinate system used in data representation and mapping is the World Geodetic System (WGS) 1984 which uses the earth centre mass as the coordinates origin. This coordinate system was chosen based on its compatibility with other coordinate systems and tested transformation tools that allow for the integration of different datasets from different sources. It is also used for international and national data representation and mapping. The international accuracy on the whole earth is set to be within a $2 \mathrm{~cm}$ range.

\subsubsection{Field Survey Data Collection}

Field surveys were carried out in the study to collect data on current waste management practices within Sunyani and its environs. The focus was laid on evaluating the current situation, researching parameters important for the site identification and collect data which could have been used for increasing the research accuracy. The information was elaborated from expert interviews with the managers of waste on site who included the Village chiefs, the manager and employees of the Waste Management Company (Zoomlion) mandated to collect and dispose-off waste in Sunyani, as well as observations and fieldtrips to waste disposal sites. The interviews were held without standardized questionnaires from eight (8) communities and were personalized according to the interview partner, in order not to limit responses from interviewees. The focus was set on the disposal sites and their impact on the surroundings, as well as the reasons for deciding to dump generated waste on a specific location. The locations within the study area where the interviews were conducted have been shown in Figure 1.

\subsubsection{Data Analysis Procedures}

\section{Land use and land classification}

The maximum likelihood supervised classification tool was used to generate the land use classes for the Sunyani Municipality. Training Samples of ground truth data of 88-point coordinates were obtained from google earth and used to train sample points on the acquired Landsat 8 imagery to generate a signature file. The signature file contained identified classes and their pixel values which assigned values to other cells based on their spectral response in the image. Six classes were emphasized in order to maximize the accuracy and not to overload the classification with classes which are not necessary for the model.

Accuracy Assessment of the land use classification

Accuracy of the classified land use and land cover were assessed based on the equations below as presented by (Rwanga \& Ndambuki, 2017):

Overall accuracy and Kappa Coefficient $(K)$

$$
\begin{gathered}
\text { Overall accuracy }=\frac{\text { Total number of correct classified }}{\text { Total number of pixels }} \times 100 \\
K=\frac{N \sum_{i=1}^{n} m_{i, i}-\sum_{i=1}^{n}\left(G_{i} C_{i}\right)}{N^{2} \sum_{i=1}^{n}\left(G_{i} C_{i}\right)}
\end{gathered}
$$


where:

- $i$ is the class number.

- $N$ is the total number of classified pixels that are being compared to ground truth.

- $m_{i, i}$ is the number of pixels belonging to the ground truth class $i$, that have also been classified with a class $i$.

- $C_{i}$ is the total number of classified pixels belonging to class $i$.

- $G_{i}$ is the total number of ground truth pixels belonging to class $i$.

\subsubsection{Modelling the Suitable Areas}

The modelbuilder in ArcGIS 10.6.1 software was used to execute the function to generate the final suitability map. It combined different tools in ArcGIS to produce a simple model structure. The model was in a workflow of tools connected and strung together to enter output data of one tool as input data for another (Figure 2). The modelbuilder was used in the suitability analysis because of the attributes it possesses.

\subsubsection{Weighting of Parameters Used for Suitable Site Selection Exclusion Criteria}

The relevance of single parameters varies when they are compared to each other therefore a weighting according to their impact, applicability and relevance is required.

The following criteria were set to exclude areas likely to be used for waste disposal sites due to their significance and were based on the guidelines from the German and American law regarding disposal site identification, which could be adapted to waste disposal in Ghana. The original parameter ranges given by the laws have been modified on basis of the report by the United Nations Environment Programme (UNEP, 2005) and according to the provided data from the surveys of the current waste disposal situation. These criteria were: distance to settlements $(\mathrm{x}>100 \mathrm{~m})$; distance to airports $(\mathrm{x}>1.5 \mathrm{~km})$; restricted areas such as national parks, military areas; and wetlands and floodplains locations.

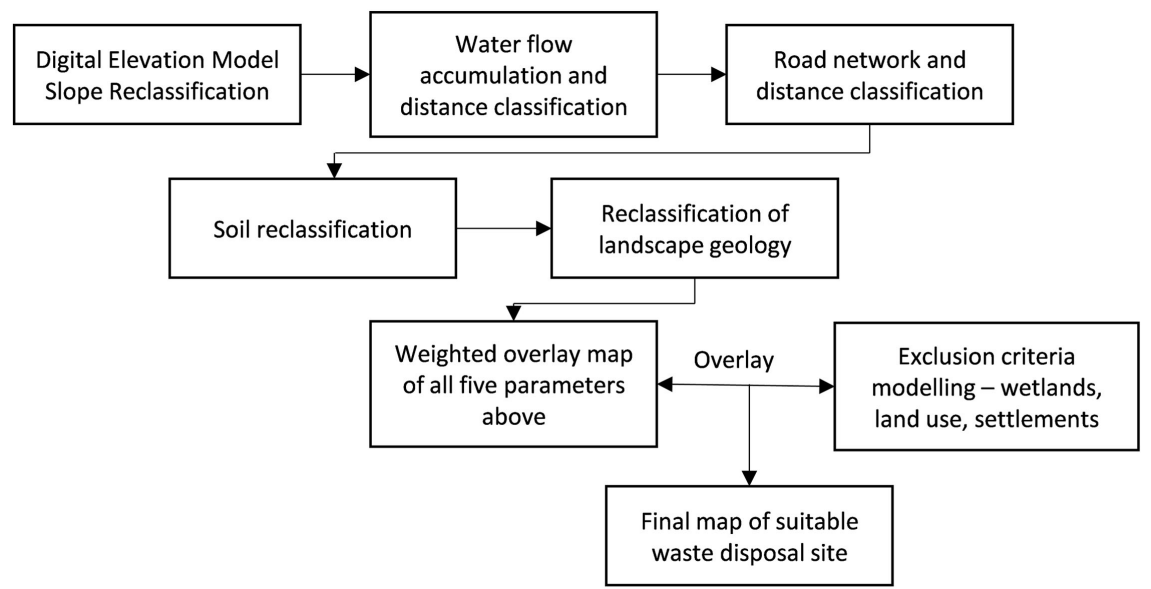

Figure 2. Flowchart of the modelbuilder (Author's own construct, 2019). 
Combined data of the locations of the towns in a shapefile, OSM data and with data obtained from satellite imagery were used to execute the exclusion operation.

The distance from the probable site to any settlement was set to a minimum of $100 \mathrm{~m}$. This was based on the data gathered in the survey distances which suggested that distances above $100 \mathrm{~m}$ were impracticable due to insufficient transportation possibilities for parts of the population. Additionally, the dense tropical vegetation around the towns could function as a buffer to keep odours and debris that might emanate from the disposal sites within bounds. The minimum distances to airports were set to 1.5 kilometres based on the American EPA standards of siting disposal sites around airports where piston driven aircrafts are used and have few dates in flight schedule.

A provided map of the forest reserves in Ghana by the Forestry Department of Ghana was used to perform a restriction analysis for reserved areas. Forest reserves are similar to national parks by definition of the Ghanaian law and have to be protected from environmental pollution by any means. Therefore, these areas were branded as restricted to disposal sites.

Floodplains and wetlands were analysed using data derived from satellite imagery classification and DEM data. All classified wetlands were set to be natural wetlands around calculated rivers in a buffer zone of $100 \mathrm{~m}$ based on the water supply by close surface water bodies and linked groundwater tables.

\section{Weighting and Composition of the dataset}

For better understanding and to simplify the model the individual datasets (Water, Soil, Geology, Topology and Connection to the catchment area) used to define the terrain characteristics were merged into complexes that represent the designated weighted parameters.

The distances to the water bodies, in this case, rivers, streams and creeks, were determined according to the order of the streams. Small streams demand smaller distances as they can be temporary dried out, use as floodway or have decreased impact on the surrounding environment. The distances were set as follows: Stream order $1+2: 50 \mathrm{~m}, 100 \mathrm{~m}$ and $150 \mathrm{~m}$; Stream order 3: $100 \mathrm{~m}, 150 \mathrm{~m}$ and $200 \mathrm{~m}$; Stream order $4+5+6: 200 \mathrm{~m}, 300 \mathrm{~m}$ and $400 \mathrm{~m}$.

The soil complex included in the analysis consists of three different datasets which were the depth of the soil to the bedrock, the soil type and the clay content. These datasets were weighted with dissimilar influences in percent. The soil type dataset was weighted $20 \%$ as least influential due to its poor resolution and age. The depth to bedrock data was weighted higher (i.e. 30\%) due to its better resolution and the fact that it serves as a buffer between the bedrock and the disposal site. The most influential rated soil dataset was the clay content. The resolution was $250 \mathrm{~m}$ equal to the bedrock data but the significance for the identification of disposal sites was set as $50 \%$, being the most influential due to their low permeability and above average sealing capabilities.

The geological parameter consists of the map of the presented geology and the types were weighted according to their hydraulic conductivity. The geometric 
mean was calculated for the ranges of the hydraulic conductivities $[\mathrm{m} / \mathrm{d}]$ as presented by (US EPA, 1993) which could be adopted to the Ghana system. These were presented as: Metamorphic rocks: $3.2 \times 10^{-6}$; Sandstones: $10^{-3}$; and Granitoids: $10^{-9}$. To increase accuracy local indifferences were taken into consideration and data on the geological formations were analysed before deciding on a specific location.

For the topology analyses, slopes were computed in percentage values from which classification ranges were derived. The slopes were classified according to their suitability for disposal sites and these classes ( 0 and 6 and above, 1 and 5 and 2 to 4 ) are presented in Table 2.

Connection to catchment area was analysed by calculating the distances to roads on basis of a logarithmic scale from $25 \mathrm{~m}$ to $400 \mathrm{~m}$, as specified in the Technical manual of US Environmental Management Agency on solid waste disposal facility criteria (US EPA, 1993). The distances to the roads were set to $25 \mathrm{~m}, 50 \mathrm{~m}, 75 \mathrm{~m}, 100 \mathrm{~m}, 150 \mathrm{~m}, 200 \mathrm{~m}, 300 \mathrm{~m}, 400 \mathrm{~m}$ and above $400 \mathrm{~m}$. The range distances up to $400 \mathrm{~m}$ were chosen based on the simple methods of road construction in the study area where one grader and a wheel loader could prepare a road, and mostly the conditions on such roads are undesirable (Kusi et al., 2016). Construction and maintenance costs were kept at a payable level so that greater distances from roads are still favourable. The same machinery is needed for the preparation of the disposal site location.

\section{The Weighting of the parameters}

The weighting of the five different parameter complexes was carried out in two steps in order to overlay and weigh the parameters as compared to each other described (Weg, 2013) for the German system.

The first step was the creation of weighted datasets for the parameters to ensure comparability. Within this process, the resolution of the image was adjusted according to the most accurate resolution in order to provide the highest possible resolution of the output dataset.

The weighting was carried out in a three divided process to determine the suitability from bad over fair to good. A three-step weighting was chosen based on the fair accuracy of the given data and simplified decision making for the lo$\mathrm{cal}$ authorities. For the overall weighting, the values listed in Table 3 were obtained. These are weighting systems working in the German and Northern hemisphere environment but are adapted to the Ghanaian environment in the best interest for environment and human health (Weg, 2013).

Table 2. Slope classification for suitability analyses of disposal sites in Sunyani.

\begin{tabular}{cc}
\hline Suitability & Slopes (\%) \\
\hline Bad & 0 and 6 and above \\
Fair & 1 and 5 \\
Good & 2 to 4
\end{tabular}

Source: (US EPA, 1993). 
Table 3. Overall weighting of parameters used in the identification of suitable waste disposal site in the Sunyani Municipality.

\begin{tabular}{cc}
\hline Parameter complex & Weighting (\%) \\
\hline Water (wetlands and distances) & 32 \\
Connection to catchment area & 28 \\
Topology & 23 \\
Soil & 10 \\
Geology & 7 \\
\hline
\end{tabular}

\section{Results and Discussion}

\subsection{Survey Analyses of Current Waste Disposal within the Sunyani Municipality}

The survey results which were obtained through interactions of the people within the Municipality and field observations revealed that disposal sites placement varies according to their size and the catchment area. Even though the survey data was not taken through rigorous statistical analyses, they provided a good overview of the situation under study and informed the weightings on the parameters considered for the suitability analysis of dumping sites in the Sunyani Municipality. Details of the analysed survey are as follows:

\subsubsection{Illegal Dumpsites}

The smallest sites were found within settlements where they are used for temporary depositing and combustion of the waste if the site is filled up, as shown in Figure 3(a). These sites have no fencing giving room for scavengers to dig through the heaps and dislocate the waste. The composition of the waste is characterized by plastic bags and packaging plastic debris. The organic matter is decomposing in between or is being burned.

These illegal dumpsites are characterized by close distances to catchment areas, lack of any proper management and site identification is carried out on basis of empty areas and convenience for transportation. These same issues listed are associated with small dumpsites but have increased impacts on the environment due to size and volume (Dladla et al., 2016).

Figure 3(b) was taken in close proximity to settlements which are located about 25 meters to the left side of the scene presented. The domestic animals of the surrounding settlements are frequently visiting the site for foraging, which a characteristic of such situations (Frazzoli et al., 2010).

\subsubsection{Community Collection Containers}

The official Community Collection Containers are located inside or on the borders in walking distances $(<100 \mathrm{~m})$ of communities. As shown in Figure 3(c), the containers provide storage of the waste until the collection by the local waste management company. The containers are collected on basis of schedules that are unreliable leading to waste often being deposited next to overflowing 


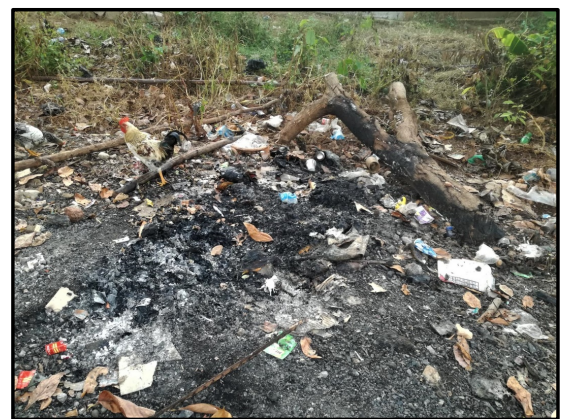

(a)

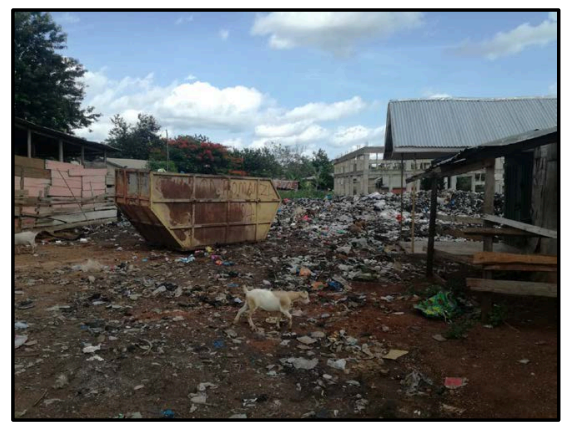

(c)

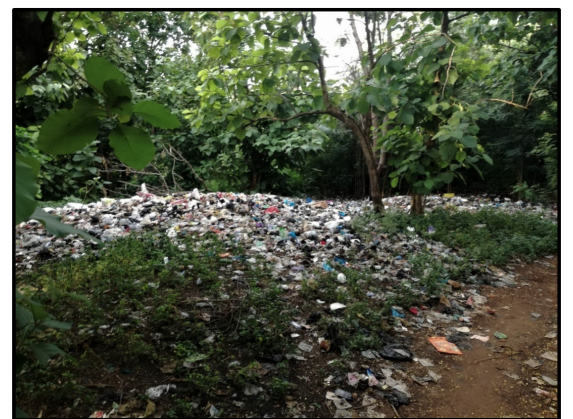

(b)

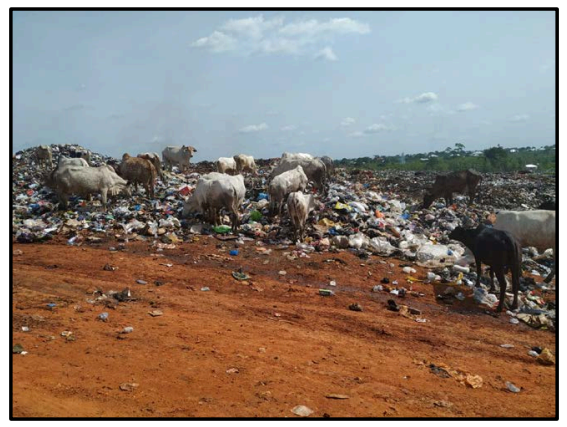

(d)

Figure 3. Current waste disposal sites available in the Sunyani Municipality. (a) Illegal dumpsites in Sunyani; (b) Illegal dumping site close to settlements; (c) Community collection container in Sunyani; (d) Official dumpsite in Sunyani.

containers. Due to its central location domestic animals (like the goat seen the picture) eat from the debris thereby posing risks to these animals since most of the food they feed on at these dumpsites may be highly contaminated (Ogbuene et al., 2013).

\subsubsection{Official Disposal Site}

The official dumpsite for the Sunyani Municipality is managed by a Waste Management Company (Zoomlion Ghana Limited), in cooperation with the local governmental regional office for waste management. However, the site is not being fenced and gates are not installed at the entrance (Figure 3(d)). This allows wildlife and other domestic animals to enter the premises causing a great nuisance in the catchment. The site itself has no fixed borders or areal restrictions and has developed with the accumulating waste, which is dumped in a pattern based on the freeing up space due to combustion, erosion or compression of the waste.

Through a transect walk across the vicinity of the official dumpsite, it was observed that small-scale businesses have been set up in close proximity to this dumpsite by people who dig into the waste searching for resaleable or reusable/recyclable disposed items. Their activities result in unintended separation of waste for the waste management company and help to reduce the amount of generated waste at the site. Nevertheless, they are exposed to harmful substances that may pose risk to their health (Addo et al., 2015). 
Even though the impacts of the waste on the surrounding environment for the current waste disposal was not conducted in this study, the noticeable risks on the environment and human health are the regular combustions of the waste (as seen in the pictures (Figure 3)) which releases thick black smoke with a chemical scent, depending on the type of waste being burned. Dispersion of waste by animals and wind is an issue on site. It could worsen the impacts on the environment and health of people living within the disposal site and even beyond the official borders. This is because sealing and coverage of the deposits with soil or artificial foils are not being carried out which leads to increased dispersion of pollutants from the dumpsite threatening the safety of environs (Figueiras et al., 2009).

\subsection{Modelling of Suitable Waste Disposal Site}

\subsubsection{Elaboration of Required Data}

Land use and land cover classification based on satellite imagery resulted in a land use and land cover map showing the six classes of relevant to this study as shown in Figure 4. The land use which was highlighted for the purpose of the exclusion criteria were forest areas, settlements and wetlands which were protected from the siting of dumpsites. Overall Accuracy and Kappa Coefficient (k) of the land use classification were $81.97 \%$ and $0.78 \%$ respectively (Table 4 ), signifying that the classified land uses were reliable to be included in the suitability analysis.

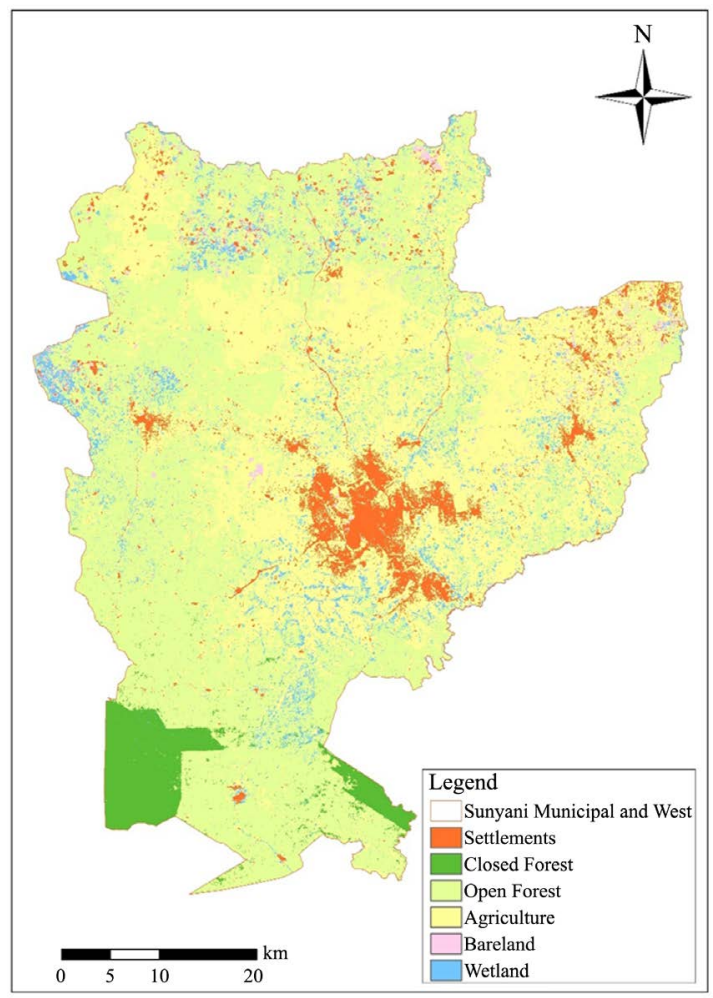

Figure 4. Map of classified land use and land cover of the Sunyani Municipal for the year 2019 (Author's own construct, 2019). 
Table 4. Area coverage of land use/cover classes in Sunyani Municipality.

\begin{tabular}{ccccc}
\hline Classes & Area $\left(\mathrm{km}^{2}\right)$ & Percent $(\%)$ & Overall Accuracy & Kappa Coefficient \\
\hline Closed Forest & 53.88 & 3.44 & & \\
Open Forest & 307.35 & 19.63 & 81.97 & 0.78 \\
Wetland & 173.03 & 11.05 & & \\
Agriculture & 724.10 & 46.25 & \\
Settlement & 50.27 & 3.21 & \\
Bareland & 256.91 & 16.41 & \\
Total & 1565.55 & 100.00 & \\
\hline
\end{tabular}

\subsubsection{Analysis of Factors Considered in the Exclusion Criteria}

Results from the modelbuilder in modelling and identifying the locations excluded from the suitability analysis have been presented in Figure 5 . These locations according to the land use/cover assessment are closed forest $\left(53.88 \mathrm{~km}^{2}\right)$, open forest $\left(307 \mathrm{~km}^{2}\right)$, wetlands $\left(173.03 \mathrm{~km}^{2}\right)$ and settlements $\left(50.27 \mathrm{~km}^{2}\right)$ representing a total percentage land coverage of 37.34 (Table 4). Figure 5 shows the single parameters which were set in the exclusion criteria. The distances of 100 $m$ to the settlements increased the excluded area (Figure 5(d)). This observation may be attributed to the expansion of towns from the city centre into the rural and peri-urban communities due to urbanization (Liu et al., 2010). This situation puts a lot of restrictions on available space for other activities such as the siting of waste disposal sites, especially where the urban sprawl is uncontrolled and unplanned and citizens are allowed to put up structures anyhow (Badoe, 2015), which is a characteristic of the study area.

The land use and land cover classification show that the land usage in the northern reserves is predominantly characterized by a wide range of restricted usages (Forests and wetlands) as compared to the southern reserves (Figure 4). This leaves the availability of space for consideration of the siting of the dumpsites in the Municipality to move towards the western part of the study area away from settlements as much possible (Figure 5(d)). Smaller and more scattered exclusion areas are the wetlands, floodplains and rivers (Figure 5(b)). The rivers are situated almost equally across the whole investigation area. The wetlands have hotspots along the biggest rivers and in the southern part, close to the forest reserve. The wetlands were excluded because they represent temporary floodplains as well as artificial and natural ponds. The water resources are too precious and rare that protection of those water bodies is vital for protecting the environment and the local residents from hazardous pollutants (Heathcote, 2009). These water resources are used for drinking water production and are used for daily household consumptions by nearby communities.

\subsection{Locations of Possible Suitable Disposal Sites}

Site identification for waste disposal has to be carried out by the responsible local authority but suggestions can be drawn from Figure 7 which shows suitable 


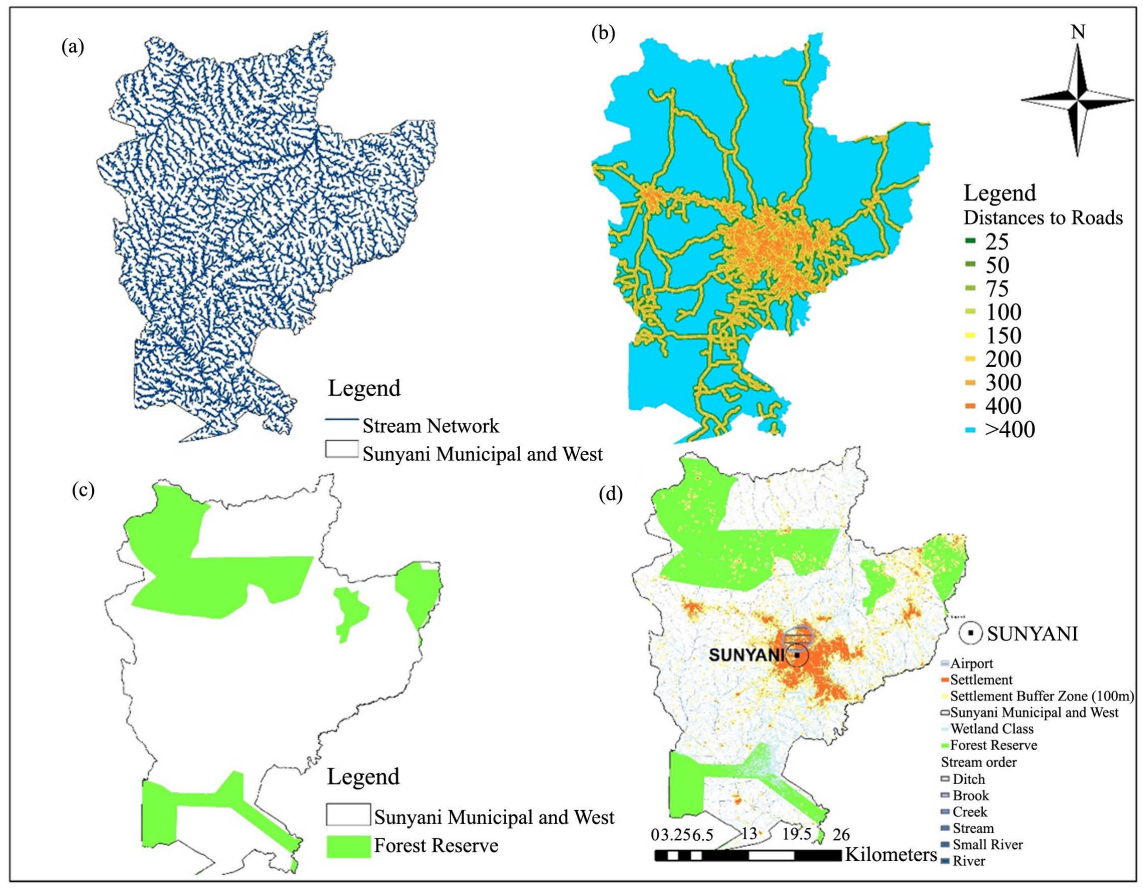

Figure 5. Map of excluded areas (Author's own construct, 2019).

potential sites where waste could be dumped and have reduced negative impacts on the safety of the environment. The areas have been rated based on the overlaying and weighting of the five parameter complexes (Water, Soil, Geology, Topology and Connection to the catchment area). The protection of the water bodies is the highest aim and the decision on how far to choose the distances depends on the policies on water bodies protection by the Ghana Environmental Protection Agency (EPA, 2016). All distances demand a leachate treatment nevertheless, and do not guarantee a $100 \%$ protection of the water bodies. Weighting of the parameters placed a higher emphasis on water since proximity to water bodies is very critical in siting dumpsites due to possible pollution of the water bodies by harmful substances from the dumpsites through erosion or leaching. Proximity to nearby settlements will also cause air pollution and affect the health of inhabitants and was also rated high. In addition, the provided settlement ranges $(25 \mathrm{~m}, 50 \mathrm{~m}, 75 \mathrm{~m}, 100 \mathrm{~m}, 150 \mathrm{~m}, 200 \mathrm{~m}, 300 \mathrm{~m}, 400 \mathrm{~m}$ and above $400 \mathrm{~m}$ ) were weighted in such a way that closer areas have higher scores based on the fact that in case a disposal site is placed in a close distance, expenses for road constructions are minimized and the connectivity to the collection area is guaranteed and therefore transportation costs are kept at a comparable low level. Clayey soils were regarded as the highest influential soil parameter because they have a better retention potential of pollutants and can therefore filter off harmful chemicals that may leach into nearby groundwater but was given a weighted influence of $10 \%$ to allow some silt to check runoff (Jidere et al. 2012). The construction of disposal sites on clayey soils is also less cost-intensive due to simple soil movements (US EPA, 1993). The hydraulic conductivities indicate groundwater flows with slow velocities for the existing geology. In this study, the grani- 
toids were set to be more suitable for disposal site locations due to their lower values for the hydraulic conductivity (Mejías et al., 2009) which result in slower contaminations speeds in case of leachates. Topological analyses presented the slope conditions suitable for a dumpsite. The $0 \%$ slopes make drainage almost impossible, except with a structural intervention that a suitable outcome could be produced. The slopes with over $6 \%$ are too steep to guarantee the safety of the surroundings and erosion may take its toll in such areas. Slopes with $1 \%$ or $5 \%$ were set as a transition range because simple constructional procedures would be able to establish a suitability. A good slope for disposal sites is within $2 \%$ to $4 \%$ and was considered for the analysis.

The most suitable identified sites have been marked green (Figure 7). Correlations between the proximity to settlements and roads are noticed especially alongside the highways and around settlements as the green areas are bordering the excluded areas (Figure 5(d)). Sites with reduced suitability are marked in yellow and consist of parameters that are overlapping and may interfere with another. The dominant parameter in these areas has to be determined by examination of all the parameters. In the yellow areas, a correlation between distance to roads and suitability can be observed (refer to Figure 6(b)) as areas with less road connectivity have lessened suitability. The red marked areas are highly unsuitable for placing a disposal site as the weighting indicates that several parameters do not meet the requirements for a proper waste disposal location. The river system with its floodway and wetlands is recognizable because the unsuitable areas are bordering almost every stream. Figure 6(a) is showing the river network and the distances which are weighted for suitability and this data is correlating with the red marked areas (Figure 7). The unsuitability is furthermore increased by steeper slopes around the water bodies due to erosion and decreased density of roads in these areas (see Figure 6(b) and Figure 6(c)).

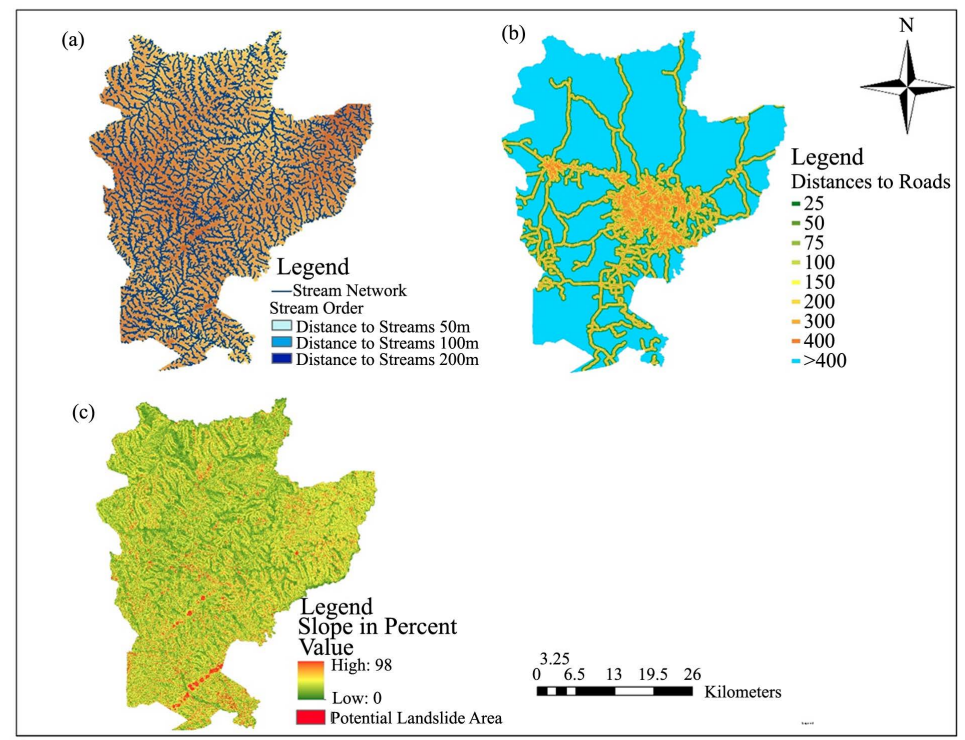

Figure 6. Maps of water bodies (a); Distances to roads (b) and slope conditions in the Sunyani municipality (Author's own construct, 2019). 


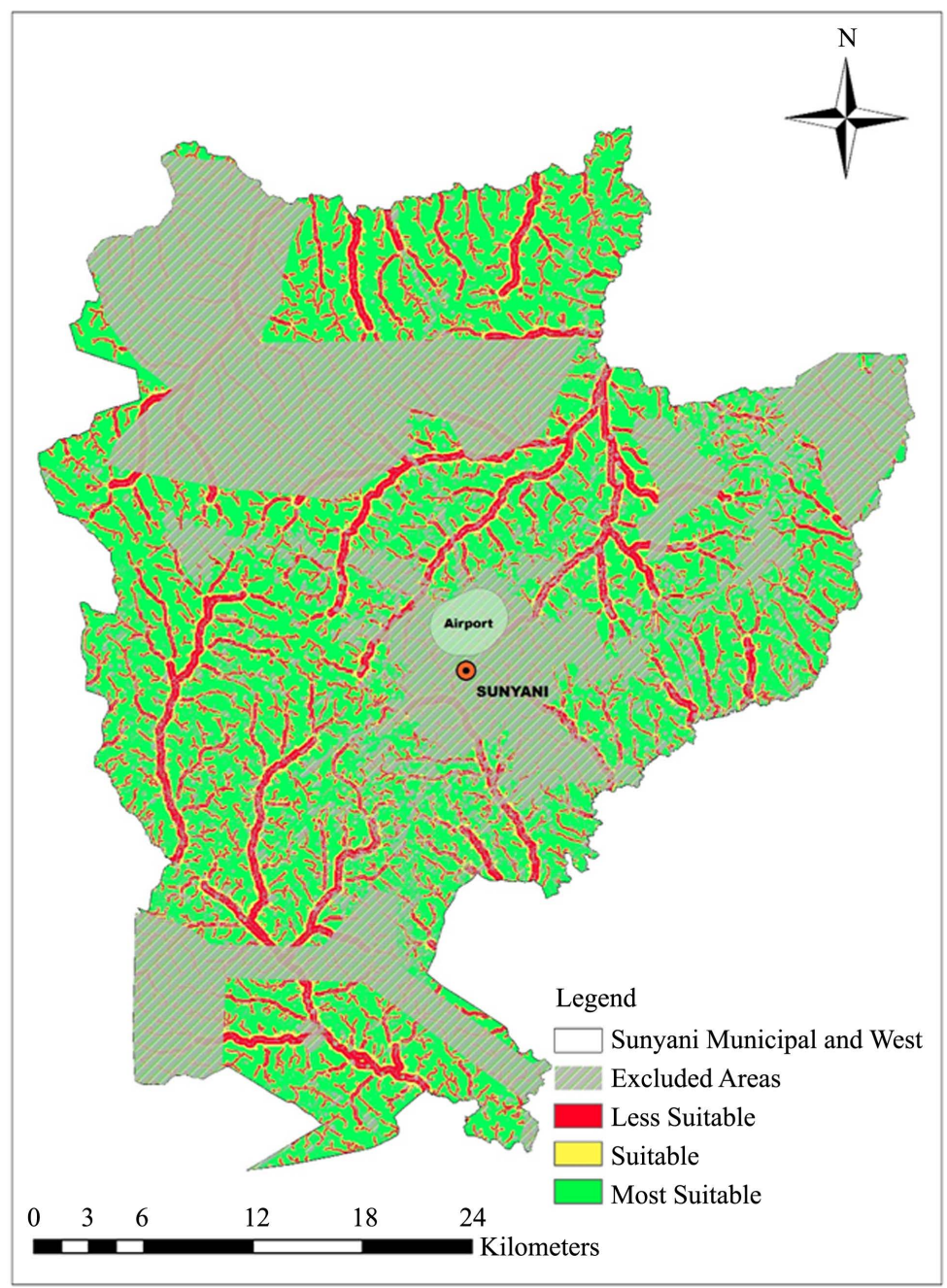

Figure 7. Final map of the potential suitable waste disposal locations in the Sunyani Municipality (Author's own construct, 2019).

\section{Conclusion}

The study was conducted to identify potential sites suitable for the disposal of generated waste in the Sunyani Municipality through field surveys and GIS-based modelling. Analyses of the survey confirmed the identified problem of improper waste disposal in the Municipality and provided an expert view that contributed to the selection of weighted parameters considered during the GIS modelling of the suitable sites. Overview of the survey depicted random placement of dumpsites which only considered transportation distances in their siting.

The model builder within ArcGIS was used to analyse five important parameters (distances to water bodies and catchment area, topology, soil and geology of the area under investigation) that need to be considered in siting locations for dumping waste. The model produced a suitability map that gives a first impression on potential location sites and is able to be adjusted by waste managers according to their preferences due to the model flexibility. The obtained results are 
meant to provide guidelines for local authorities as a first analysis of an investigation area and so, for specific locations, a further in-depth research is needed. The suitable sites give an indicator for sites with the least possible environmental impact. The accuracy could be increased if other parameters e.g. predominant wind direction or distances inside the collection areas, are included.

\section{Limitation of the study}

1) Land ownership rights were not included in the study since focus was on environmental impacts. For a full identification process, the cadastre must be included in order to determine whether usage rights can be obtained or the site can be bought and can be included in the modelbuilder.

2) All guidelines and laws, mentioned in this study, dictate that any surface water bodies have to be excluded from the identification processes of disposal sites.

3) The distances to roads are set on a logarithmic scale and actual construction costs for roads in Ghana are not included. The type of road needed may also vary.

4) The issues raised during the survey in the disposal waste management have been analysed but not in depth. Obvious issues are noticed and are mostly correlated with the design of the disposal site, for example fencing, drainage and leachate treatment.

\section{Conflicts of Interest}

The authors declare no conflicts of interest regarding the publication of this paper.

\section{References}

Addo, I., Adei, D., \& Acheampong, E. (2015). Solid Waste Management and Its Health Implications on the Dwellers of Kumasi Metropolis, Ghana. Current Research Journal of Social Sciences, 7, 81-93. https://doi.org/10.19026/crjss.7.5225

Adu-Boahen, K., Atampugre, G., Antwi, K., Osman, A., Osei, K., Mensah, E., \& Adu-Boahen, A. (2014). Waste Management Practices in Ghana: Challenges and Prospect, Jukwa Central Region. International Journal of Development and Sustainability, 3, 530-546.

Alganci, U., Besol, B., \& Sertel, E. (2018). Accuracy Assessment of Different Digital Surface Models. ISPRS International Journal of Geo-Information, 7, 114. https://doi.org/10.3390/ijgi7030114

Badoe, C. (2015). The Challenges of Waste Management in Ghana: EPA's Perspective. http://www.todaygh.com/challenges-waste-management-ghana-epas-perspective

Bhada-Tata, P., \& Hoornweg, D. A. (2012). What a Waste? A Global Review of Solid Waste Management (No. 68135, pp. 1-116). Washington DC: The World Bank.

Dladla, I., Machete, F., \& Shale, K. (2016). A Review of Factors Associated with Indiscriminate Dumping of Waste in Eleven African Countries. African Journal of Science, Technology, Innovation and Development, 8, 475-481.

https://doi.org/10.1080/20421338.2016.1224613

EPA (2016). Hazardous and Electronic Waste Control and Management Act (ACT 917). 
Ghana: Environmental Protection Agency.

Ferronato, N., \& Torretta, V. (2019). Waste Mismanagement in Developing Countries: A Review of Global Issues. International Journal of Environmental Research and Public Health, 16, 1060. https://doi.org/10.3390/ijerph16061060

Figueiras, J., Gonçalves, M., Mateus, A., Marques, F., Santos, F., \& Mota, R. (2009). Initial Stages of Pollutants Dispersion around Municipal Waste Disposal Facilities: A Case Study in Northern Portugal. International Journal of Environment and Waste Management, 4, 341-365. https://doi.org/10.1504/IJEWM.2009.027401

Frazzoli, C., Orisakwe, O. E., Dragone, R., \& Mantovani, A. (2010). Diagnostic Health Risk Assessment of Electronic Waste on the General Population in Developing Countries' Scenarios. Environmental Impact Assessment Review, 30, 388-399. https://doi.org/10.1016/j.eiar.2009.12.004

GSS (2012). 2010 Population and Housing Census: Summary Report of Final Results. Service GS, Ghana Statistical Service.

Heathcote, I. W. (2009). Integrated Watershed Management: Principles and Practice. Hoboken, NJ: John Wiley \& Sons.

Henry, R. K., Zhao, Y. S., \& Dong, J. (2006). Municipal Solid Waste Management Challenges in Developing Countries-Kenyan Case Study. Waste Management, 26, 92-100. https://doi.org/10.1016/j.wasman.2005.03.007

Idowu, I. A., Atherton, W., Hashim, K., Kot, P., Alkhaddar, R., Alo, B. I., \& Shaw, A. (2019). An Analyses of the Status of Landfill Classification Systems in Developing Countries: Sub Saharan Africa Landfill Experiences. Waste Management, 87, 761-771. https://doi.org/10.1016/j.wasman.2019.03.011

ISRIC (2017). ISRIC Soil Information: Africa Soil Information Service. Soil Property Maps of Africa at $250 \mathrm{~m}$ Resolution.

https://www.isric.org/projects/africa-soil-information-service-afsis

Jerie, S., \& Zulu, S. (2017). Site Suitability Analysis for Solid Waste Landfill Site Location Using Geographic Information Systems and Remote Sensing: A Case Study of Banket Town Board, Zimbabwe. Review of Social Sciences, 2, 19-31. https://doi.org/10.18533/rss.v2i4.99

Jidere, C., Unagwu, B., \& Nnebedum, T. (2012). Distribution of Some Heavy Metals in the Soil-Clay-Silt Particle Fractions of Refuse Dumpsites in Enugu State. Agro-Science, 11, 32-37. https://doi.org/10.4314/as.v11i2.5

Kusi, E., Nyarko, A. K., Boamah, L. A., \& Nyamekye, C. (2016). Landfills: Investigating Its Operational Practices in Ghana. International Journal of Energy and Environmental Science, 1, 19-28.

Liu, Y., Liu, Y., Chen, Y., \& Long, H. (2010). The Process and Driving Forces of Rural Hollowing in China under Rapid Urbanization. Journal of Geographical Sciences, 20, 876-888. https://doi.org/10.1007/s11442-010-0817-2

Mejías, M., Renard, P., \& Glenz, D. (2009). Hydraulic Testing of Low-Permeability Formations: A Case Study in the Granite of Cadalso de los Vidrios, Spain. Engineering Geology, 107, 88-97. https://doi.org/10.1016/j.enggeo.2009.05.010

Miezah, K., Obiri-Danso, K., Kádár, Z., Fei-Baffoe, B., \& Mensah, M. Y. (2015). Municipal Solid Waste Characterization and Quantification as a Measure towards Effective Waste Management in Ghana. Waste Management, 46, 15-27. https://doi.org/10.1016/j.wasman.2015.09.009

Miwornunyuie, N., Kabo-Bah, A. T., \& Akpoti, K. (2016). Effect of the Sunyani Municipal Waste Dumpsite on Surface Water Quality. Global Journal of Bio-Science and Bio- 
technology, 5, 1-11.

Nnorom, I. C., \& Osibanjo, O. (2008). Overview of Electronic Waste (e-Waste) Management Practices and Legislations, and Their Poor Applications in the Developing Countries. Resources, Conservation and Recycling, 52, 843-858.

https://doi.org/10.1016/j.resconrec.2008.01.004

Ogbuene, E. B., Igwebuike, E. H., \& Agusiegbe, U. M. (2013). The Impact of Open So a Case Study. Journal of Advance Academic Research, No. 1, 43-53.

Rodic-Wiersma, L. (2013). Guidelines for National Waste Management Strategies: Moving from Challenges to Opportunities (108 p.). United Nations Environmental Programme.

Rwanga, S. S., \& Ndambuki, J. M. (2017). Accuracy Assessment of Land Use/Land Cover Classification Using Remote Sensing and GIS. International Journal of Geosciences, 8, 611. https://doi.org/10.4236/ijg.2017.84033

Singh, J., Laurenti, R., Sinha, R., \& Frostell, B. (2014). Progress and Challenges to the Global Waste Management System. Waste Management \& Research, 32, 800-812. https://doi.org/10.1177/0734242X14537868

Talsness, C. E., Andrade, A. J., Kuriyama, S. N., Taylor, J. A., \& Vom Saal, F. S. (2009). Components of Plastic: Experimental Studies in Animals and Relevance for Human Health. Philosophical Transactions of the Royal Society B: Biological Sciences, 364, 2079-2096. https://doi.org/10.1098/rstb.2008.0281

UNEP (2005). Closing an Open Dump Site and Shifting from Open Dumping to Controlled Dumping and to Sanitary Land Filling: United Nations Environment Programme. United Nations Environmental Programme.

UNHSP (2003). The Challenge of Slums: Global Report on Human Settlements. United Nations Human Settlements UN-HABITAT.

US EPA (1993). Solid Waste Disposal Facility Criteria: Technical Manual. Office of Solid Waste and Emergency Response, EPA 530-R-93-017.

Weg, K. (2013). Gesetz zur Förderung der Kreislaufwirtschaft und Sicherung der umweltverträglichen Bewirtschaftung von Abfällen (Kreislaufwirtschaftsgesetz-KrWG). 